PROBLEMS

OF MANAGEMENT IN THE $21^{\text {st }}$ CENTURY Vol. 9, No. 2, 2014

150

\title{
IMPROVING THE ERGONOMIC QUALITY OF AR-BASED E-LEARNING SYSTEMS: A TASK-BASED DESIGN APPROACH
}

\author{
Costin Pribeanu \\ National Institute for Research and Development in Informatics - ICI Bucharest, \\ Romania \\ E-mail: pribeanu@ici.ro
}

\begin{abstract}
Augmented reality (AR) is a challenging technology for e-learning. Nevertheless, the benefits of AR in terms of increased engagement and motivation could be undermined by a low ergonomic quality. A challenge for designers is to provide students with a usable AR environment that is able to support an effective and efficient achievement of their learning goals. A user-centred design approach requires understanding users and the tasks they perform. This analysis focuses on task modelling and presents a task-based approach to the development of a Chemistry application implemented on an AR teaching platform. The task model enables an analysis of critical task sequences, helps to prevent potential usability problem, and provides with a basis for a task-based approach to evaluation.
\end{abstract}

Key words: ergonomic quality, user-centred design, usability, task modelling, e-learning, augmented reality.

\section{Introduction}

The ISO standard 25010 distinguishes between a product quality model and a quality in use model (ISO, 2010). The quality in use is closely related with five outcomes of interaction with the system: effectiveness, efficiency, satisfaction, safety, and context comprehensiveness. The product quality model defines eight characteristics: functional suitability, performance efficiency, compatibility, usability, reliability, security, maintainability, and portability. Usability refers to the extent to which a product can be used by specified users to accomplish specified goals with effectiveness, efficiency, and satisfaction in a specified context of use (ISO, 2010). At a more detailed level, usability refers to products that are recognized as appropriate, are easy to learn how to use, easy to operate, protect users from errors, and have an aesthetic user interface.

Augmented reality integrates real and virtual worlds (computer generated images) and is featuring a real time 3D interaction targeting all senses (Azuma, 1997). AR technologies are creating new opportunities for the designers of e-learning systems (Cheng \& Tsai, 2013; Wu et al., 2013). By integrating various real objects from the traditional school into a computing environment, AR favours learning by doing which is more captivating and motivating, especially for the young learner (Vos et al., 2011; di Serio et al, 2013). The ergonomic quality is a key factor influencing the outcomes of an AR-based application (Dunser \& Billighurst, 2011; Bai \& Blackwell, 2012; Pribeanu, 2014). By ergonomic quality we refer to the extent to which a system is easy to understand, easy to learn how to use, and easy to operate. The augmented reality technology may create additional problems that are due to the specific devices (seethrough screen, projectors, and cameras) as well as to the integration of specific real objects. 
In general, designing for usability is not easy for applications based on augmented reality and requires a user-centred approach to design and evaluation (Bach \& Scapin, 2004; Gabbard \& Swann, 2008). This means to understand users and tasks, to carefully develop specific interaction techniques, and to evaluate with actual users.

The ARiSE (Augmented Reality in School Environments) project created an Augmented Reality Teaching Platform (ARTP) for primary and secondary schools. The main goal was to test the pedagogical effectiveness of using the AR technology in class. A specific objective was to test the extent to which ARTP is enhancing students' motivation to learn. Three application prototypes were developed onto ARTP. The second application implemented a Chemistry learning scenario. The underlying interaction paradigm for this scenario was "building with guidance" aiming at understanding the periodic table of Chemical elements, the structure of atoms / molecules, and the chemical reactions.

In order to ensure a user-centred approach, a task model has been developed for each application prototype. The objective of this paper is to present the task-based design approach and to highlight the benefits of task modelling for the ergonomic quality of the application. The approach is illustrated with an example (the task of building molecules and Chemical compounds from atoms).

The rest of this paper is organized as follows. The platform and experiment are briefly presented in the next section. Then the notation used for task modelling and some previous and related work in this area are summarized. Then the task modelling approach is presented and discussed. The paper ends with conclusion and future research directions.

\section{Platform and Learning Scenario}

The AR platform consists of 4 independent modules organized around a table on which real objects are placed (Wind et al., 2007). The platform has been registered by Fraunhofer IAIS (Spinnstube ${ }^{\circledR}$ ). The Chemistry scenario is using two kinds of real objects: a periodic table and a set of coloured balls (4 colours) symbolizing atoms. A remote controller Wii Nintendo has been used as interaction tool for selecting a menu item.

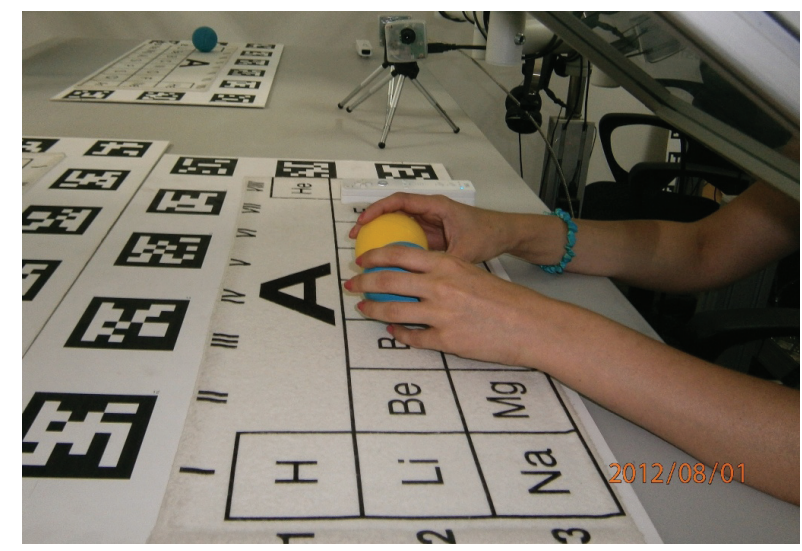

\section{Figure 1: Student performing an exercise in Lesson 2.}

The learning scenario for Chemistry has an introductory part and three lessons. The first lesson is about the chemical structure of the atoms and has 2 exercises. The second lesson is about forming molecules and has 8 simple exercises. The third lesson is about chemical reactions and has 3 exercises. Each lesson has several exercises. Additional details about the pedagogical goals, lessons, and exercises could be found in (Vilkonis et al., 2008). Each workplace has its 
Costin PRIBEANU. Improving the Ergonomic Quality of AR-Based E-Learning Systems: A Task-Based Design Approach

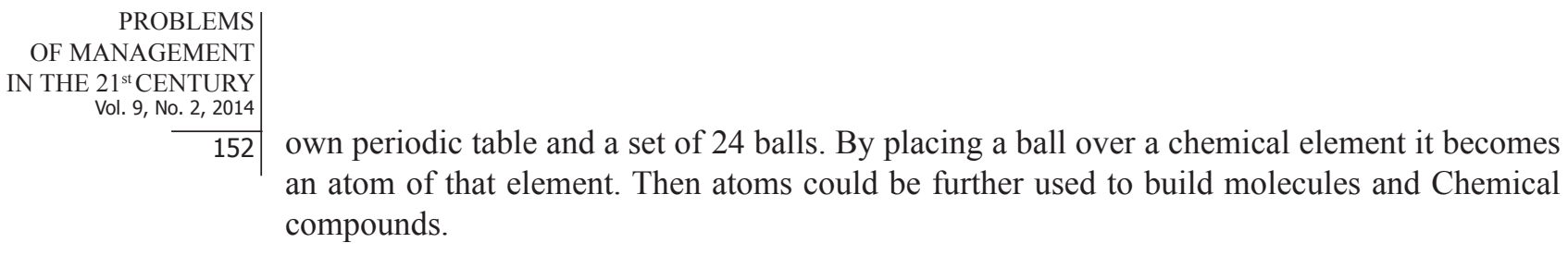

\section{Task Modelling Notations and Tools}

Task modelling is an important concern for developers aiming at producing usable systems. A task is an activity performed by people to accomplish a certain goal. A task could be further decomposed resulting in smaller tasks corresponding to lower level goals. Task decomposition is usually represented as a tree. Inner tasks are said to be composite (or abstract, complex) while the leaves are elementary tasks, which in turn are decomposed in actions performed upon objects. Task models as resulted from early task analysis could provide with useful information for improving user guidance and task compatibility.

In a user centred design approach the user interface of an interactive system is designed based on the information provided by the task model. Existing task models show a great diversity as regarding formalisms and depth of analysis. There are various objectives that underlie the elaboration of each task model thus featuring a certain type of representation (Pribeanu \& Vanderdonckt, 2002):

- Inform design about potential problems of usability, as in HTA (Annett \& Duncan, 1967).

- $\quad$ Evaluate the human performance, as in GOMS (Card et al., 1983).

- $\quad$ Aid design by providing a more detailed task model describing task hierarchy, objects used and knowledge, as in TKS (Johnson et al., 1992) or GTA (van der Veer et al., 1996).

- $\quad$ Generate a prototype of a user interface, as in Adept (Wilson et al., 1993).

- In a previous work (Pribeanu, 2005) a task modelling approach for user interface design has been proposed that is based on three decomposition levels:

- A functional level that results from mapping of application functions onto user tasks.

- $\quad$ A unit task level that results from the decomposition of functional tasks regardless the constraints imposed by a target hardware and software platform (goal hierarchy).

- A basic task level that results from the decomposition of unit tasks, which are, carried on by using interaction techniques available on a target platform (operational task structure).

- A unit task is defined as a task the user really wants to perform (Card et al, 1983). The distinction between unit tasks and basic tasks is important for at least two reasons: (a) it follows the design process, by separating the "what-to-do" knowledge acquired during task analysis from the "how-to-do-it" knowledge acquired during task design; (b) basic tasks are pointing to abstract interaction objects thus rendering visible in the task model in the interaction flow.

- In a recent work, Molina et al. (2013) proposed the Collaborative Interactive Application Notation - CIAN and a metamodel for an associated modelling tool supporting interactive group work. Their conceptual framework distinguishes between four modelling perspectives: organizational (organizational structure), process (work structure and work flow), data (information manipulated), and interaction (interaction with the presentation layer). From a process modelling perspective, they consider individual tasks, group work tasks, collaborative tasks, and cooperative tasks. 
- $\quad$ There are relatively few approaches to task modelling for AR-based applications. As pointed out by Trevisan et al. (2004) it is more difficult to model tasks in the context of two worlds of interaction (real and virtual) and multiple sources of information. They suggested an integration of several notations in order to express the specific task characteristics in AR.

- Dupuy-Chessa et al. (2010) proposed a software engineering method using the ASUR notation for task modelling. They distinguish between abstract scenarios and concrete scenarios. A concrete scenario describes the user tasks, the supporting devices, and the interaction artefacts. The scenario is checked for usability based on paper and software prototypes.

- $\quad$ Several notations and tools exist for task modelling. Concurrent Task Trees - CTT (Paterno \& Santoro, 2002) is a notation that is using temporal operators, to link sibling tasks. This is different from other notations where operators are describing parent-children relationship. CTTE is an interactive environment providing a graphical notation to specify tasks, roles, and objects as well as the task hierarchies. There are five kinds of task categories: abstract, interaction, application, user, and cooperative. The task categories are presented in Table 1.

Table 1. Task categories in CTTE.

\begin{tabular}{lcccc}
\hline Abstract & Interaction & Application & User & Cooperative \\
\hline 3 & n & & & \\
\hline
\end{tabular}

The temporal operators defined by CTT are presented in Table 2. The notation distinguishes between unary and binary operators. There are several restrictions in combining binary and unary operators. For example, the combination $\mathrm{T} 1 *>>\mathrm{T} 2$ is not allowed, since $\mathrm{T} 2$ will be never performed. Also, optional tasks are not allowed in the left and right side of the operators $\mid>$, [> and [ ].

Table 2. Temporal operators in CTTE.

\begin{tabular}{ll}
\hline \multicolumn{1}{c}{ Binary operators } \\
\hline Choice & $\mathrm{T} 1[] \mathrm{T} 2$ \\
\hline Order independency & $\mathrm{T} 1|=| \mathrm{T} 2$ \\
\hline Interleaving & $\mathrm{T} 1|| \mathrm{T} 2$ \\
\hline Synchronization & $\mathrm{T} 1|[]| \mathrm{T} 2$ \\
\hline Enabling & $\mathrm{T} 1>>\mathrm{T} 2$ \\
\hline Enabling with info passing & $\mathrm{T} 1[]>>\mathrm{T} 2$ \\
\hline Disabling & $\mathrm{T} 1$ [ T2 \\
\hline Suspend / resume & $\mathrm{T} 1 \mid>\mathrm{T} 2$ \\
\hline & \\
\hline Optional & Unary operators \\
\hline Iteration & $\mathrm{T} 1]$ \\
\hline
\end{tabular}


PROBLEMS

OF MANAGEMENT

IN THE $21^{\text {st }}$ CENTURY Vol. 9, No. 2, 2014

154

With CTTE a designer can create task trees and specify task properties such as: task type, frequency, and estimated execution time. An important feature is the XML output capability that makes CTTE a useful tool for the handling of mappings between the task model and other models. An example is given in (Pribeanu, 2006) where a set of mapping rules between task and domain models has been used for automate derivation of task model fragments from the domain model.

A first approach to task modelling in the ARiSE project was taken for the Biology learning scenario. The idea was to model each task by using the CTT notation and to link a tabular description for each task model with the graphical representation. The approach is described in a previous work (Pribeanu et al., 2007).

\section{Task-based Approach}

In order to present our task-based approach we will take as an example an exercise from the second lesson of the Chemistry scenario. The task goal is to build a molecule from atoms. The description for the second lesson is summarized in Table 3 (at unit task level) and is based on the scenario defined by Vilkonis et al. (2008).

At the beginning of each lesson the student is given a vocal explanation on how to perform the tasks. Then, a list of exercises is displayed from which the student can select one by pressing the back button of the remote control. A short explanation is given for the exercise and the Chemical symbol of the molecule is displayed on the screen. Then s (he) takes a ball and places it on the periodic table. After watching the chemical structure and checking the chemical symbol of the atom (visual feedback) the student confirms by pressing the back button of the remote controller. The task is repeated for each atom required. Then the student brings the atoms together to build the molecule. If the result is correct, (s) he receives a positive audio feedback and the symbol is highlighted in green.

Table 3. Scenario description for an exercise in Lesson 2.

\begin{tabular}{llll}
\hline Task name & User input & System output & Description / observations \\
\hline Perform exercise & $\begin{array}{l}\text { Select the exercise } \\
\text { from the menu }\end{array}$ & $\begin{array}{l}\text { Vocal explanation, displays the } \\
\text { symbol of the molecule }\end{array}$ & $\begin{array}{l}\text { Select the exercise by pressing the } \\
\text { back button of the remote control }\end{array}$ \\
\hline Select atom & $\begin{array}{l}\text { Place a ball on the } \\
\text { table and confirm }\end{array}$ & $\begin{array}{l}\text { Displays the atom structure and } \\
\text { atom symbol; waits for confirmation }\end{array}$ & $\begin{array}{l}\text { Iterative abstract task, to be } \\
\text { performed until all needed atoms } \\
\text { are specified }\end{array}$ \\
\hline Quild molecule & $\begin{array}{l}\text { Place all atoms on } \\
\text { the table }\end{array}$ & $\begin{array}{l}\text { If the result is correct, displays the } \\
\text { augmentation, symbol; vocal mes- } \\
\text { sage to congratulate the student }\end{array}$ & $\begin{array}{l}\text { Iterative user task, to be performed } \\
\text { until all atoms needed are brought } \\
\text { together }\end{array}$ \\
\hline & $\begin{array}{l}\text { Select "Quit" from } \\
\text { the menu }\end{array}$ & Return to the list of exercises & $\begin{array}{l}\text { Can repeat the exercise or select } \\
\text { a new one }\end{array}$ \\
\hline
\end{tabular}

Prior to build the task model the scenario is analysed for usability. Good ergonomic quality requires user guidance throughout the interaction process. Appropriate user guidance requires prompting the user for input and providing adequate feedback. As the screen space is a critical resource for desktop AR systems, providing with vocal output (prompting, explanations, and feedback) is very useful.

The task model is specified in CTTE according to the scenario description. There are four unit tasks: Exercise, Select atom, Build molecule, and Quit. The model could be checked in CTTE for consistency. This way, it is possible to detect tasks that are not reachable. Then, 
it is possible to simulate the task execution which is useful both for designers (check if task implementation is consistent with the scenario requirements) and evaluators. The simulated scenario (tasks actually performed) could be saved for later use. Prior to evaluation, it is useful to understand task requirements and check if the user input and system output are well synchronized. The task model for Lesson 2 is presented in Figure 2.

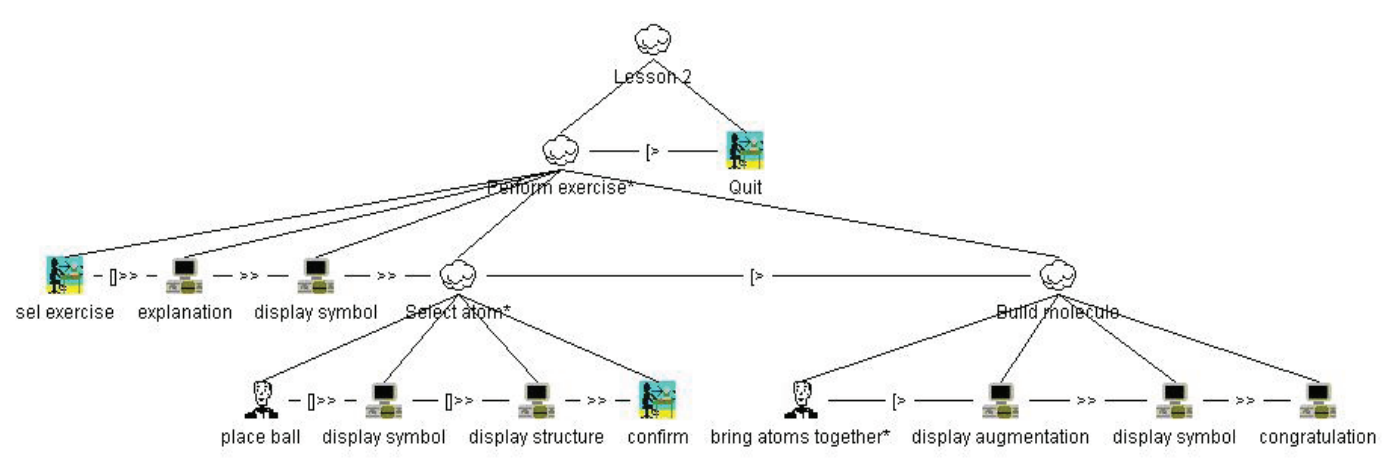

\section{Figure 2: Task model for Lesson 2.}

In order to inform designers on potential usability problems, the operational task structure for each unit task should be carefully analysed. In Table 4 a template is presented that is intended to guide designers for usability. The description is done at unit task level. The same template could be used by evaluators to prepare the evaluation and to identify actual usability problems.

Table 4. Potential usability problems - Select atom.

\begin{tabular}{lll}
\hline Basic Task & Potential problem & Solution \\
\hline Select atom & Lack of user guidance & $\begin{array}{l}\text { Vocal explanation at unit task level: attention to use balls with } \\
\text { different colour for each atom and confirm }\end{array}$ \\
\hline Place ball & Same colour for more atoms & $\begin{array}{l}\text { Vocal feedback if the same colour has already been assigned } \\
\text { (warning) }\end{array}$ \\
\hline & $\begin{array}{l}\text { The ball is placed on } \\
\text { another element }\end{array}$ & Semantic feedback: augmentation showing the atom structure \\
\cline { 2 - 3 } Display symbol & Same colour for more atoms & Visual feedback: atom symbol - coloured ball (prevent) \\
\cline { 2 - 3 } & $\begin{array}{l}\text { The user does not perceive } \\
\text { it }\end{array}$ & $\begin{array}{l}\text { Vocal feedback on where the symbol is displayed (e.g. top-right } \\
\text { area) }\end{array}$ \\
\hline Display structure & Visual perception & Augmentation should be accurate \\
\hline \multirow{2}{*}{ Confirm } & Wrong assignment & $\begin{array}{l}\text { Vocal feedback regarding how to fix it (use the same ball again } \\
\text { and ignore the warning) }\end{array}$ \\
\hline
\end{tabular}

For this lesson, atom selection is a critical task sequence. Users should be protected from making errors. First of all, the user has to confirm that the atom is the one s (he) wants to select based on the augmentation. Second, this is done after the user input by providing a multimodal feedback that is targeting both the visual and auditory channels. Third, this is done by warning the user if the atom was already selected. Then, the user should be able to fix a selection error. This is done by repeating the selection using a ball of the same colour and ignoring the warning. 
Costin PRIBEANU. Improving the Ergonomic Quality of AR-Based E-Learning Systems: A Task-Based Design Approach

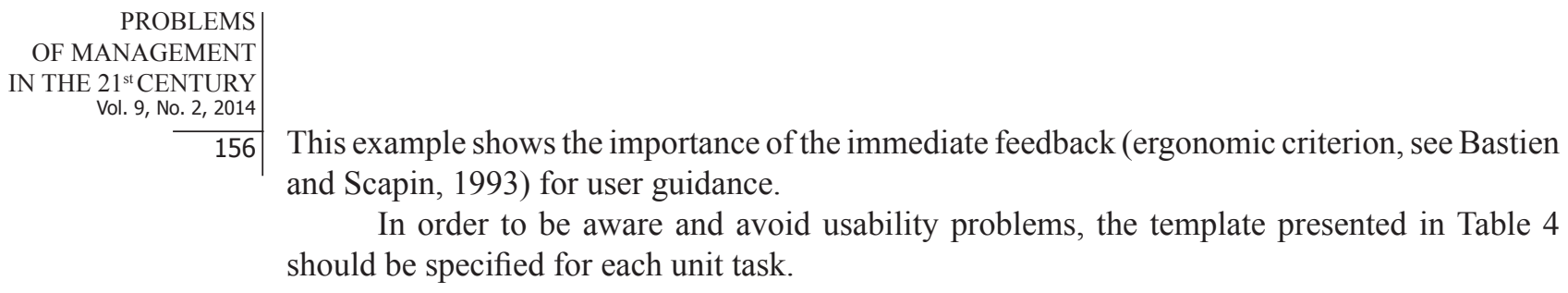

\section{Conclusions}

AR technologies are expensive and require a lot of research and design effort to develop visualization and rendering software. A specific feature is the mix of traditional AR techniques with specific (dedicated) interaction techniques used to integrate domain specific real objects. In order to improve the ergonomic quality of e-learning applications, a user-centred approach is needed from scenario specification to implementation and evaluation. Using a task-based specification, incorporates human factors early in the design process, facilitates communication between designers and evaluators, and helps in fixing usability problems.

The quality of user interfaces is a trade-off between utility and usability. A user-centred approach to design and evaluation could significantly improve the ergonomic quality of e-learning applications. This means, to focus on users' tasks and goals. In this paper a taskbased approach has been presented, that is, using the CTTE task modelling tool together with a tabular description of tasks and an analysis of potential usability problems. The approach is useful for both developers and evaluators.

AR-based e-learning applications are featuring complex tasks that require both domain knowledge (e.g. understanding of Chemistry concepts) and specific knowledge of how to interact with an AR platform. Although the interaction is intuitive, the mix of real and virtual worlds may create additional difficulties for the learner as regarding the ease of use. The task based approach presented in this paper enables designers to better understand users' needs and avoid potential usability problems that could undermine the ergonomic quality and, consequently, the outcomes of AR-based learning.

\section{Acknowledgement}

We gratefully acknowledge the support of the ARiSE (FP6-027039) project, funded by the European Commission.

\section{References}

Annett, J., \& Duncan, K. (1967). Task analysis and training design. Occupational Psychology, 41, 211-227.

Azuma, R. T. (1997). A survey of augmented reality. Presence-Teleoperators and Virtual Environments, 6 (4), 355-385.

Bach, C., \& Scapin, D. L. (2004). Obstacles and perspectives for evaluating mixed reality systems usability. Workshop MIXER "Exploring the Design and Engineering of MR system", IUI-CADUI 2004, Funchal, Portugal, January 2004, n 13-16, p. pp.72-79.

Bai, Z., Blackwell, A. (2012). Analytic review of usability evaluation in ISMAR. Interacting with Computers, 24, 450-460.

Bastien, C. J. M., \& Scapin, D. (1993). Ergonomic criteria for the evaluation of human computer interfaces. Technical Report No.156, INRIA.

Card, S. K., Moran, T. P., \& Newell, A. (1983). The psychology of human-computer interaction. Lawrence Erlbaum Associates, Hillsdale, NJ, USA.

Cheng, K. H., Tsai, C. C. (2013). Affordances of augmented reality in science learning: Suggestions for future research. Journal of Science Education and Technology, 22 (4), 449-462.

Di Serio, A., Ibáñez, M. B., Kloos, C. D. (2013). Impact of an augmented reality system on students' motivation for a visual art course. Computers \& Education, 68, 586-596. 
Dunser, A., Billinghurst, M. (2011). Evaluating augmented reality systems. Ch. 13 in Furgt, B. (Ed.) Handbook of Augmented Reality. Springer, pp. 289-308.

Dupuy-Chessa, S., Godet-Bar, G., Pérez-Medina, J. L., Rieu, D., \& Juras, D. (2010). A software engineering method for the design of mixed reality systems. In The Engineering of Mixed Reality Systems (pp. 313-334). Springer, London.

ISO/IEC FCD 25010:2010. (2007). Software engineering - Software product quality requirements and evaluation (SQuaRE) - System and software quality models, JTC 1/SC 7 N4522.

Johnson, P., Markopoulos, M., \& Johnson, H. (1992). Task knowledge structures: A specification of user task models and interaction dialogues. Proceedings of Interdisciplinary Workshop on Informatics and Psychology, Austria.

Gabbard, J., \& Swann, E. (2008). Usability engineering for augmented reality: Employing user-based studies to inform design. IEEE Transactions on Visualization and Computer Graphics, 14 (3), 513-525.

Molina, A., Gallardo, J., Redondo, M., Ortega, M., Giraldo, W. (2013). Metamodel-driven definition of a visual modeling language for specifying interactive groupware applications: An empirical study. The Journal of Systems and Software, 86 (7), 1772-1789.

Paternò, F., Santoro, C. (2002). One model, many interfaces. Proceedings of CADUI'2002, Kluwer. 143154.

Pribeanu, C., \& Vanderdonckt, J. (2002). A methodological approach to task-based design of user interfaces. Studies in Informatics and Control, 11 (2), 145-158.

Pribeanu, C. (2005). An approach to task modeling for user interface design. Proceedings of World Enformatika Conference - WEC 2005, (Istanbul, 27-29 April 2005). C. Ardil (Ed.) Enformatika Vol. 5, 5-8.

Pribeanu, C. (2006). Tool support for handling, mapping rules from domain to task models. Proceedings of TAMODIA 2006, Hasselt, Belgium. LNCS 4385. Springer, 16-23.

Pribeanu, C., Vilkonis, R., \& Iordache, D. D. (2007). A task-based design approach for augmented reality systems. International Journal of Social Sciences, 2 (4).

Pribeanu, C. (2014). Usability problems affecting an enjoyable learning experience with an AR-based application. Proceedings of the IE 2014 International Conference, 122-126.

Trevisan, D. G., Gemo, M., Vanderdonckt, J., \& Macq, B. (2004). Focus-based design of mixed reality systems. In Proceedings of the 3rd annual conference on task models and diagrams (pp. 59-66). ACM.

Vilkonis, R., Lamanauskas, V., Palepsaitiene, R. (2008). The scenario of learning module "Introductory course of Chemistry" for a new learning platform based on augmented reality technology (Prototype 2). Proceedings of ICTNSE 2008, InterDok, 123-142.

Vos, N., Meijden, H., Denessen, E. (2011). Constructing versus playing an educational game on student motivation and deep learning strategy used. Computers \& Education, 56, 126-137.

Wilson, S., Johnson, P., Kelly, C., Cunningham, J., \& Markopoulos, M. (1993). Beyond hacking: A model based approach to user interface design. Proceedings HCI'93, Cambridge University Press.

Wind, J., Riege, K., Bogen, M. (2007). Spinnstube®: A seated augmented reality display system. In Proceedings of Virtual Environments 2007, IPT-EGVE 2007 - EG/ACM Symposium Proceedings, $17-23$.

Wu, H., Lee, S. W., Chang, H., Liang, J. (2013). Current status, opportunities and challenges of augmented reality in education. Computers \& Education, 62, 41-49.

Advised by Vincentas Lamanauskas, University of Šiauliai, Lithuania

Received: May 29, 2014

Accepted: August 25, 2014

Costin Pribeanu
PhD., Senior Researcher, National Institute for Research and Development in Informatics - ICI Bucuresti, Bd.Mareşal Averescu Nr.8-10, 011455 Bucureşti, Romania. E-mail: pribeanu@ici.ro Website: http://rochi.ici.ro/pribeanu/ 